\title{
VIVÊNCIA COM PAIS DE ADOLESCENTES: UMA PROPOSTA DE CURSO QUE FACILITA O RELACIONAMENTO
}

\author{
Célia Maria Ferreira da Silva Teixeira *
}

TEIXEIRA, C.M.F.DA S. Vivência com pais de adolescentes: uma proposta de curso que facilita o relacionamento. Rev. latino-am. enfermagem, Ribeirão Preto, v. 4, n. 2, p. 73-85, julho 1996

A autora descreve a experiência na realização de curso de curta duração, destinado a pais de adolescentes e profissionais que lidam com essa faixa etária, $O$ grupo de participantes foi formado por 18 mães de diferentes papéis profissionais: diretora de escola do I grau, coordenadora pedagógica de escola de I e II graus, pedagogas, estudante de pedagogia e estudantes de psicopedagogia. Os motivos das escolhas apresentados pelos participantes centravam-se em dificuldades no relacionamento entre os pais e seus filhos e na busca de formas mais satisfatórias e funcionais da díade pais - filhos. A autora utilizou o referencial sistêmico sobre a adolescência e a metodologia psicodramática com o objetivo de facilitar o entendimento da temática em questão. O curso possibilitou informações sobre os aspectos da adolescência, a repercussão desta no contexto familiar, bem como, propiciou troca de opiniões, e o compartilhar de dúvidas e sentimentos de insegurança frente à tarefa de serem pais de adolescentes, permitindo a construção de novas formas dos pais perceberem, sentirem e expressarem seus afetos.

UNITERMOS: adolescência, pais, família

\section{INTRODUÇÃO}

A adolescência tem merecido a atenção de vários estudiosos e tem sido descrita como uma fase de desenvolvimento do ser humano, onde ocorrem as

* Mestre em Educação Escolar Brasileira - Faculdade de Educação / Universidade Federal de Goiás. Psicóloga Clínica do NECASA / U.F.G. - Profa. Assistente da Fac. de Educação U.F.G. 
maiores transformações no indivíduo em nível corporal, mental e social. A literatura acerca do assunto mostra-se vasta, contudo, não se pode afirmar o mesmo, quando se trata das relações entre pais e filhos no contexto familiar. O período da adolescência requer muitas mudanças nos padrões internacionais entre adolescentes, seus pais e a família.

Com as mudanças operadas na sociedade a família ressente-se dos momentos de viver o aconchego do espaço reservado para os seus membros, o que conduz ao distanciamento entre as pessoas, dificultando o encontro familiar.

A família considerada um sistema vivo é formada por vários subsistemas: o subsistema conjugal, o subsistema filhos e o subsistema fraterno (MINUCHIN, 1982). Como um sistema vivo, encontra-se inserida em outros sistemas, como é o caso da sociedade. Há, pois, uma interdependência constante e permanente entre o sistema família e a sociedade. O tempo todo a família determina algumas das características da sociedade e sofre as influências dos padrões vigentes nessa mesma sociedade. Falar de mudanças na sociedade, nos remete às mudanças que a própria família vive como sistema vivo ao longo de sua existência.

Historicamente, o grupo familiar tem mudado, não só quanto à distribuição do poder, mas também quanto ao número de componentes. Cada vez mais, a família toma-se um grupo formado por um casal e filhos. MARX (1971), propôs a gradativa separação do indivíduo do grupo, graças a uma divisão cada vez maior do trabalho, que se reflete na própria estrutura do grupo familiar.

Estudos na área da terapia sistêmica familiar (MINUCHIN, 1992) traz o conceito de Ciclo Vital Familiar (CVF). Tal noção ajuda-nos a compreender um pouco da história da família, que possui um ciclo vital: nasce, cresce, amadurece e morre, podendo ou não dar surgimento a uma nova família. Esse ciclo identifica os estágios de desenvolvimento da interação da família, apresenta os movimentos vivenciados pelos elementos que a compõem expressando as mudanças possíveis de ocorrerem. E constituído pelos seguintes momentos ${ }^{\star *}$ :

01) Processo de crescimento e desvinculação do jovem adulto;

02) Namoro (contato com outros sistemas; novas relações);

03) Noivado (decisão consciente de assunção dos vínculos que se desenvolvem, a escolha inconsciente do parceiro);

04) Casamento (os recém-casados e as ligações entre as famílias através do matrimônio);

05) O nascimento do primeiro filho;

06) A família com criança(s) pequena(s);

07) A família com adolescentes;

08) Os filhos adultos (processo de crescimento e desvinculação);

09) O casamento dos filhos (as ligações entre as famílias através do matrimônio);

10) Os pais sozinhos, a velhice e a função de avós;

11) Os cuidados da senilidade;

12) A morte.

**Etapas do CVF citadas pela Profa. Julia F. Bucher em Curso de Terapia Conjugal e Familiar - Go. 1992. 
MINUCHIN (1992) apresenta os seguintes estágios do CVF, organizados em tomo do crescimento e desenvolvimento dos filhos.

1) Formação do casal;

2) Nascimento do $1^{\circ}$ filho;

3) Família com crianças pequenas;

4) Família com filhos adolescentes;

5) Saída dos filhos;

6) "Ninho vazio".

No que se refere à etapa - família com crianças pequenas - existem diferenças daquela com filhos adolescentes. Na fase com filhos adolescentes, a família entrará em contacto com o subsistema de amigos. Muitas vezes, nestes momentos, encontrará dificuldades em assimilar o grupo de amigos de seus filhos adolescentes. Assim sendo, a família interage com um sistema forte, muitas vezes, competitivo, que é o grupo de companheiros. Questões de autonomia e controle devem ser renegociados em todos os níveis.

Mudanças na sociedade, na família, nos adolescentes, são nitidamente perceptíveis. Mas a mudança mais significativa para os pais, com certeza, se expressa na própria mudança em suas atitudes e valores. Por exemplo, mudar a percepção de que ter filhos adolescentes é viver uma fase de constantes dificuldades e eternos problemas (TEIXEIRA, 1995).

Se é certo afirmar que há um considerável número de pessoas, que expressa dificuldades no exercício do papel de pais de adolescentes, não será correto afirmar que há inúmeras oportunidades dos pais serem informados e de se sentirem aliviados, reduzindo assim a ansiedade frente à tarefa de educar. O que se constata mediante relatos de pais é a existência do mito de que, ter um filho adolescente toma- se uma tarefa árdua e desafiadora. Por outro lado, são poucas as oportunidades dos pais trocarem informações em um contexto que os ajudem a enfrentar as dificuldades em serem pais, que possibilitem trocas de informações sobre as coisas que os incomodam.

Nossa vivência com adolescentes, seus pais e suas famílias, quer seja em atendimento clínico ou mediante o contato feito em escolas de I e II graus das redes pública e particular de Goiânia, tem revelado grande distanciamento entre país e filhos. Por outro lado, o contato com os adolescentes e seus familiares atendidos no NECASA*** contribuiu para aumentar, cada vez mais, o interesse em realizar

\footnotetext{
***NECASA (Núcleo de Estudos e Coordenação de Ações para Saúde do Adolescente) é um serviço de assistência integral ao adolescente, com funcionamento no Hospital das Clínicas da Universidade Federal de Goiás. Entre as atividades assistenciais encontram-se o atendimento nos ambulatórios geral para adolescente e o ambulatório de ginecologia e obstetrícia. Desenvolve também atividades de ensino (graduação e pós-graduação médica) e atividades educacionais, mediante a realização de cursos de educação sexual para adolescentes e pais.
} 
atividades, quer seja, em nível de encontros, quer seja em cursos ou palestras que visassem o desenvolvimento das pessoas no papel de pai e de mãe.

Esse relato insere-se dentro de uma proposta de trabalho junto a pais de adolescentes, objetivando veicular a informação acerca da dinâmica própria do adolescente, bem como a criação de um espaço para a liberação de conteúdos emocionais, por parte dos pais, frente à tarefa de educar.

Por acreditar profundamente, que o trabalho do psicólogo não deva restringir-se aos espaços do consultório ou às demandas de uma instituição, o convite feito pela Faculdade de Educação****, para ministrar um curso destinado a pais de adolescentes, foi continente aos nossos propósitos.

A idéia do curso "Vivência com pais de adolescentes" nasceu, portanto, da constatação de que os pais conhecem muito pouco acerca do desenvolvimento dos filhos, que se tornam adolescentes. Estes apresentam características peculiares tanto do ponto de vista orgânico, quanto do ponto de vista psico-social. Tais aspectos passam a exigir dos adultos que rodeiam os adolescentes outras formas de conduta, diferentes daquelas até então utilizadas.

\section{METODOLOGIA}

O curso aliou informação à ação, pautando-se nos princípios do psicodrama de MORENO (1975). Foi dada às pessoas a oportunidade de perceberem, mediante a ação psicodramática os medos, receios, angústias e condutas disfuncionais que vem habitualmente mantendo no contexto familiar. O psicodrama, indiscutivelmente, possibilitou a leitura relacional das dificuldades vividas na família. A essência do paradigma moreniano situa o homem como um ser em relação, utilizando técnicas específicas, tais como: dramatização, inversão de papéis, solilóquios, etc. Oferece, portanto, aos participantes e ao grupo, a oportunidade de se obter "insights" sobre formas relacionais, conflitos interpessoais, bem como, as dificuldades inerentes à pessoa e às tarefas próprias do papel de pais de adolescente.

Foram trabalhadas as seguintes unidades temáticas: 1) retorno à própria adolescência, revendo-a, para compreender a adolescência do filho; 2) ciclo vital familiar; 3) noção básica sobre família (o subsistema pais - o subsistema filhos -o subsistema fraterno); 4) características bio-psico-sociais do adolescente; 5) temas polêmicos na educação: o ficar, a questão dos limites (como evitar atropelos).

${ }^{\star * * \star A}$ A Faculdade de Educação é uma unidade de ensino, pesquisa e extensão da Universidade Federal de Goiás, destinada à formação de educadores em nível de graduação e pós-graduação 
Programação do curso - o curso compreendeu carga horária de 6 horas, distribuída em dois dias consecutivos, constante de parte teórica e de situações vivenciais.

$1^{\circ} \mathrm{dia}$

Antes de iniciar as atividades a coordenadora solicitou aos participantes que escrevessem seus nomes de forma legível, em folhas de papel sulfite escolar dobrados ao meio. Em seguida, pediu-lhes que colocassem as folhas nas carteiras (parte anterior) a fim de facilitar a identificação e comunicação dos participantes. A coordenadora realizou, por sua vez, o mesmo procedimento.

1 - Apresentação da coordenadora - esta etapa abrange dois momentos: no primeiro momento - coordenadora falou das razões pelas quais aceitou o convite para ministrar o curso. Referiu-se a seu interesse em função, do seu papel profissional e a constante proximidade com adolescentes. Referiu-se ainda, a sua crença no trabalho com pais, como possibilidade de desenvolvimento de novas formas interacionais com conseqüente melhora na comunicação entre pais e filhos. No segundo momento, passou a informar que o curso incluiria parte teórica e parte vivencial.

2 - Apresentação dos participantes - cada participante apresentou os motivos pelos quais escolhera o curso. Em seguida, atendendo solicitação da coordenadora, cada um falou sobre suas expectativas (Enquanto as pessoas falavam, a coordenadora escrevia no quadro uma síntese das idéias expostas pelos participantes).

3 - Técnica - volta à adolescência - a coordenadora solicitou a todos que fechassem os olhos e obedecessem as seguintes consignas: focalize sua atenção sobre o seu corpo/Procure relaxar/Imagine-se frente a um espelho grande/Observe que figuras, além de você, aparecem no espelho. Pode surgir figuras do seu relacionamento familiar atual ou de sua família de origem (Enquanto falava a coordenadora colocava no chão, no meio da sala vários recortes com palavras ou frases que suscitavam situações relacionadas a pais, filhos, adolescência).

As palavras e frases:

"Há um oceano de diferenças entre eles..."

"O coração tem razões"

"Ajudar você a andar no caminho certo"

"Aconchego"

"Pequenos ditadores"

"Primeiro precisamos saber quem estuda"

"Para ajudar a viver sem culpa"

"Quando a mulher é a última a decidir"

"A vida é uma sinfonia"

"Os sentimentos dele" 
"À flor da pele"

"O equilíbrio"

"Nossos filhos"

"Do bê-a-bá ao sonho de mudar o mundo"

"Transforme-se"

"Medo, vergonha e culpa"

"Sabe como fazer seu filho comer quatro cenouras?"

"Amor \& Poder"

"Pais por opção, um amor maduro"

"Grandes saltos"

"Ajuda de fora"

"Maratona de obstáculos"

"Eu não gosto que coloquem limites na minha vida"

"Certos hábitos devem ser preservados"

"É preciso ter coragem, para revelar todos os nossos medos"

"O perigo mora ao lado"

"Esta conversa, seu filho não pode perder"

"Rivalidades fatais"

"Para trás, tensões"

"Renovar"

"Ai, se eu escutasse o que mamãe dizia"

"Mostre a ele pequenas formas de comemorar o seu grande amor"

"Soluções prontas"

"Mostre que ele tem razão"

"Amor de mãe não vê preço"

"Venha se expor"

"A arte de amar"

"Nada de mais, nada de menos"

"Sonhar faz bem para a vida"

"Ainda bem que ele é rebelde e contestador"

"As principais mudanças"

"Fique de olho"

- Após alguns instantes a coordenadora pediu a todos que lentamente abrissem os olhos e procurassem no chão as palavras ou frases que estavam mais relacionadas com a situação de cada um.

- Pediu em seguida, a cada um que comunicasse o que imaginara ter visto no espelho, passando depois para os comentários sobre as escolhas dos recortes.

- No momento seguinte os participantes trocaram opiniões, percebendo pontos de contato entre suas histórias. Reafirmam os motivos que o trouxeram ao curso.

- INTERVALO -

4 - Técnica das perguntas - (procurando seu par) - a coordenadora solicitou aos 
participantes que escolhessem entre os vários pedaços de figuras, que Ihes eram apresentadas, aquelas que lhe interessassem. (As figuras têm formas variadas e estão incompletas, cada parte contém uma pergunta). De posse dos pedaços as pessoas procuravam na sala a outra metade, formando então a figura completa. Em seguida, sentam-se conversavam, trocando opiniões sobre a pergunta formulada.

Exemplo*****:

Figura

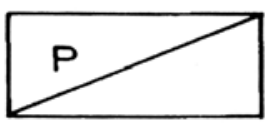

Figura

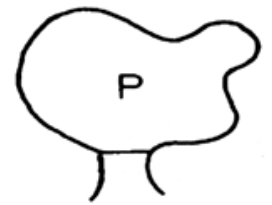

Figura

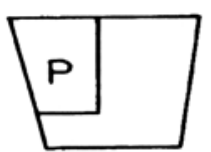

Figura

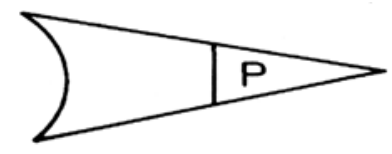

P: Porque é difícil serem pais de adolescentes hoje?

P: Existe diálogo entre você e seus filhos?

P: Você fala sobre sexo com seus filhos?

Você sabe a diferença entre namorar e "ficar" para os adolescentes?

Outras perguntas:

- Como são estabelecidos os limites dentro de sua casa?

- Existem assuntos que você imagina ser difícil conversar com seus filhos?

- Para você, quais seriam as maiores dificuldades em ser adolescente hoje?

- O que você gostaria de modificar no relacionamento com seus filhos adolescentes?

- Qual a participação de sua família na educação de seus filhos?

- Você consegue entender por que os adolescentes sempre deixam suas obrigações para depois? adolescentes?

- Para você, quais seriam as transformações que ocorrem com os

*****Os exemplos acima citados foram colocados a título de ilustração 
5 - Trabalhando as etapas do ciclo vital familiar - A coordenadora fez uma breve explicação sobre os estágios que uma família passa, durante a trajetória de sua formação. Em seguida, solicita que as pessoas procurem se colocar nos lugares (estágios) que dizem mais respeito à própria situação. Neste momento, as pessoas circulavam na sala e começavam a ocupar os espaços equivalentes aos estágios do CVF.

Ao ser trabalhado o tema ciclo vital familiar os participantes obtiveram a chance de perceberem através da ação psicodramática (inversão de papéis, solilóquios) os movimentos pelos quais a família passa. A fase do CVF - família com filhos adolescentes - particularmente ofereceu aos pais a oportunidade de perceberem e sentirem, como ficam as interações em uma família, que abriga em seu interior, um filho adolescente.

6 - Teorização - Neste momento são detalhadas informações sobre:

- A noção de ciclo vital familiar;

- Conceito de família - sistema vivo;

- Conceito de subsistemas: conjugal, pais. filhos, fraterno.

Ao final das atividades do dia, a coordenadora entregou o texto "A dificuldade em serem pais (de adolescentes) hoje" (TEIXEIRA, 1994), solicitando que todos lessem o referido texto para o dia seguinte.

$2^{\circ}$ dia

1- Aquecimento - a coordenadora pergunta aos participantes o que pensaram ao vir para o curso, que sentimentos surgiram a partir das informações e vivências do dia anterior.

2- Discussão sobre o texto - "A dificuldade em serem pais (de adolescentes) hoje" - o grupo verbalizou suas impressões, referindo a adequação da temática exposta no texto.

3- Caracterização das transformações bio-psico-socíais da adolescência - neste momento a coordenadora faz explanações, com utilização de retroprojetor e projetor de "slides", acercadas transformações que ocorrem na adolescência e suas implicações no núcleo familiar.

Esta parte, bastante extensa proporcionou oportunidade aos participantes de expressarem suas dúvidas e preocupações. O momento foi rico em trocas de experiências levando o grupo a compartilhar angústias e medos. 
- INTERVALO -

4 - Quadro síntese (montagem em transparência) sobre características de ser adolescente e característica da família com filhos adolescentes.

5 - Leitura e debate sobre os dois textos: "A revolução do ficar" e "Como evitar atropelos" do livro Adolescência - o despertar do sexo. (TIBA, 1994)

6 - Momento final - Avaliação: os participantes responderam por escrito uma avaliação sobre o curso, que compreendia seis perguntas:

- Como se sentiu neste grupo, discutindo questões sobre adolescência?

- O conteúdo trabalhado atendeu suas expectativas?

- Quais os assuntos que mais lhe interessaram dentro da temática estudada? Por quê?

- O que você achou da metodologia utilizada?

- Ainda com relação à metodologia: você considera que a metodologia utilizada ajudou na aproximação dos participantes do curso?

- Que outros comentários/sugestões você apresentaria neste momento?

\section{RESULTADOS E DISCUSSÃO}

- Quanto à metodologia utilizada

O primeiro momento do curso (apresentação) facilitou a aproximação inicial entre os participantes. As colocações feitas sobre expectativas e motivações representavam um primeiro passo para que os membros do grupo se sentissem compartilhando de uma mesma experiência, identificando uns nos outros as próprias ansiedades, fantasias e medos com relação à tarefa de educar seus filhos.

Com relação à técnica do recorte que incluía, inicialmente a imagem do espelho, trouxe uma grande riqueza de conteúdo com a liberação de sentimentos. Os participantes referiram-se a imagens do espelho ligadas às figuras de sua família de origem (mãe, pai), ou às figuras da família atual (Geralmente aparecia a figura de um dos filhos, o filho adolescente). Alguns conduziram as imagens do espelho à própria adolescência, em seus aspectos característicos - mudanças corporais e novos interesses.

$\mathrm{Na}$ fase de "comunicação" sobre a escolha dos recortes ocorreram manifestações nítidas de angústias e incertezas no cumprimento da tarefa de serem país de adolescentes.

A ação dramática mostrou-se um instrumento extremamente útil, possibilitando em nível vivencial a apreensão das etapas do ciclo vital familiar. Tal 
aspecto foi perceptível por ocasião da avaliação. Ainda com relação à metodologia foi mencionado que houve "total liberdade de participação".

No fechamento do curso foi possível a verbalização, pelos participantes, dos ganhos obtidos, proporcionados pela oportunidade de serem informados e poderem se expressar e vivenciar seus anseios e preocupações.

Através da avaliação verificamos que, de uma maneira geral, os participantes ficaram satisfeitos, mas expressaram grande interesse em dar continuidade a esse tipo de curso, inclusive com carga horária maior. Sugeriram que houvesse curso dessa natureza em escolas (principalmente estaduais), com pais dos alunos.

- Quanto ao conteúdo proposto

Inicialmente percebemos que a expectativa era receber informação, ampliar conhecimentos sobre a adolescência. Observamos basicamente atitude, por parte dos participantes, mais de recebedores, o que foi sendo modificado. À medida que os temas eram vivenciados, situações conduziam à obtenção de "insights" sobre suas formas relacionais. A ênfase dada às questões sobre família foi vista como adequada e esclarecedora. Enfocar aspectos sobre o sistema familiar mostrou-se como um novo conhecimento, levando-os aperceberem a necessidade deter uma visão mais contextualizada do adolescente.

\section{CONSIDERAÇÕES FINAIS}

Parece-nos pertinente, retomar a idéia referida anteriormente sobre o mito do filho adolescente.

Sabe-se que a principal função do mito é a de "revelar os modelos exemplares de todos os ritos e atividades humanas significativas...", citado em (PACCOLA, 1994). Dito isto, imaginamos que existe uma série de condutas e procedimentos compartilhados por membros da família. Aos pais são destinados papéis e funções que encontram o seu complementar na figura do filho. Aos pais cabe a tarefa de disciplinar, corrigir, orientar, educar e... no caso de serem pais de adolescentes viverem preocupados e não raro, angustiados. Mas isto pode ser modificado, caso Ihes sejam oferecidas oportunidades de perceberem a dimensão de sua tarefa, podendo diminuir ou mesmo extinguir aspectos que servem para manutenção do mito.

Acreditamos que este curso, embora de curta duração, atingiu os objetivos pretendidos: levar os pais a refletirem sobre a sua função junto ao filho em crescimento, compreendendo-o, ampliando as possibilidades de novos padrões de interação, desfazendo mitos.

Seguem-se alguns relatos dos participantes durante a avaliação:

"O curso atendeu as minhas expectativas, às minhas angústias de como 
lidar com meus filhos, pois estava realmente perdida, sem direção".

"O curso foi além de minhas expectativas. Todas os assuntos me interessaram, desde a técnica do espelho, as técnicas de dramatização, até a leitura dos textos".

"Acho que outro curso não atenderia o que eu estava precisando".

"Abriu mais possibilidade de discutir os problemas das relações pais-filhos".

"Na verdade, a discussão dos assuntos nessa abordagem sistêmica me deixou com um gostinho de quero mais...".

"Tudo que tratamos, discutimos e partilhamos me foi muito útil e vai servir, com certeza, com auxílio para o trabalho que desenvolvo".

Os estudos sobre adolescência trazem um conjunto de informações que retratam as diversas características dos jovens, quer seja no plano biológico quer seja no plano psicológico. O leitor interessado na temática se sentirá impelido a aumentar seus conhecimentos e, ao empreender tal ação, será lançado a diversas e interessantes descobertas: o mundo do adolescente - mistura de emoções e contradições. Tudo em constante e intensa transformação. Contudo, as questões da família e o relacionamento de pais e filhos adolescentes, conta ainda com escassa bibliografia. KALINA \& GRYNBERG (1974); ZAGURY (1994); TIBA (1994); OUTEIRAL (1994); LÉVISKY (1995), reservam parte de suas obras à questão dos pais. Falam da dificuldade em serem pais, da crise que se opera no seio da família. Estes autores apresentam, sem sombra de dúvida, várias explicações sobre as condutas dos jovens adolescentes. As informações servem, como provável orientação. Mas... seria essa a forma, mas eficaz que levaria a possíveis alterações nos vínculos entre pais e filhos?

Encaminhar o adolescente, rotulado como "filho problema", ao tratamento psicoterápico garantiria mudanças de condutas, com ressonância no contexto da família? Essas são questões que, de forma incisiva, vêm juntar-se ao conjunto de reflexões no papel de psicóloga.

Não basta informar os pais sobre a adolescência. Não basta tentar amenizar as "dores" sentidas, referindo à existência da famosa, crise da adolescência. É preciso mais do que informação, é preciso construir um espaço para que pai e mãe falem, expressem com a voz e com o corpo, suas expectativas, seus medos, suas esperanças na árdua e envolvente tarefa de educar.

Foi pensando na dimensão do papel de pai e mãe, no significado e na importância de um vínculo saudável e pleno, sem barreiras, que temos realizado experiências sob a modalidade de cursos. Estes distanciam-se dos moldes tradicionais de transmissão do conhecimento. A vivência de situações tematizadas espelha um conjunto de possibilidades na modificação das relações entre pais e filhos.

A proposta do curso desenvolvido, mediante situações vivenciadas, mostrouse, não apenas como uma simples experiência, mas como um momento significativo na vida e na história das pessoas. Os resultados conduzirão, sem dúvida, à 
construção de novas formas dos pais sentirem e expressarem seus afetos para com seus filhos, podendo facilitar a grande rede de interações entre a díade pais-filhos adolescentes.

"Eu sinto que tenho que mudar com eles"

(Mãe referindo-se aos filhos adolescentes)

\section{AN EXPERIENCE OF LIFE WITH PARENTS OF ADOLESCENTS: A PROPOSAL OF A COURSE WHICH MAKES THE RELATIONSHIP EASIER}

The author describes an experience of a short term course for parents of adolescents and professionals, who deal with this age group. Participants were mothers of different professions: a principal of an elementary school, a pedagogic coordinator of an elementary and a high school, pedagogues, a student of pedagogy and students of phsyco pedagogy. The reasons for the choice presented by the participants centered in difficulties in the relationship between parents and their children and in the search for more satisfactory and functional forms of the parents - children dyad. The author made use of systemic referential about the adolescence and the phsyco dramatic methodology with the objective of making easier the understanding of the thematic in question. The course not only offered information about the aspects of adolescence, its repercussion in the family context, but also propitiated exchanges of opinions, sharing of doubts, odd feelings of insecurity faced with the task of being parents of adolescents allowing the construction of new ways for the parents o perceive, feel and express their friendship.

UNITERMS: adolescence, parents, family

\section{VIVENCIA CON PADRES DE ADOLESCENTES: UNA PROPUESTA DE CURSO QUE FACILITA EL RERACIONAMIENTO}

La autora describe experiencia en la realización de curso de corta duración, destinado a padres de adolescentes y profesionales que lidean con ese grupo de edad. El conjunto de participantes era formado por madres de diferentes profesiones: directora de 
escuela de $1^{\circ} \mathrm{grado}$, coordinadora pedagógica de escuela $1^{\circ}$ e $2^{\circ} \mathrm{grados}$, pedagogas, estudiante de pedagogía y estudiantes de psicopedagogía. Los motivos que llevaron a los participantes a escoger dicho curso fueron fundamentalmente, dificultades en el relacionamiento entre los padres y sus hijos y en la búsqueda de formas más satisfactorias y funcionales de la dupla padre-hijo. La autora utilizó el referencial sistémico sobre la adolescencia y la metodología psicodramática con el objeto de facilitar la comprensión del tema referido. El curso posibilitó informaciones sobre los aspectos de la adolescencia, la repercusión de ésta en el contexto familiar, así como, propició intercambio de opiniones, compartir dudas, sentimientos de inseguridad frente a la tarea de ser padres de adolescentes, permitiendo la construcción de nuevas formas de percibir por parte de los padres, sentir ) expresar sus afectos.

TÉRMINOS CLAVES: adolescencia, padres, familia

\section{REFERÊNCIAS BIBLIOGRÁFICAS}

01. KALINA, E.; GRYNBERG, H. Aos pais de adolescentes. Rio de Janeiro: Francisco Alves, 1985.

02. LÉVISKY, D.L. Adolescência: reflexões psicanalíticas. Porto Alegre: Artes Médicas, 1995.

03. MARX, K. A crise da família e o futuro das relações entre os sexos. Rio de Janeiro: Paz e Terra, 1971.

04. MINUCHIN, S. Famílias: funcionamentos e tratamento. Porto Alegre: Artes Médicas, 1982.

05. MORENO, J.L. Psicodrama. São Paulo: Cultrix, 1975.

06. OUTEIRAL, J.O. Adolescer: estudos sobre adolescência. Porto Alegre: Artes Médicas, 1994.

07. PACCOLA, M.K. Leitura e diferenciação do mito. São Paulo: Summus, 1994.

08. TEIXEIRA, C.M.F.S. Tarefa difícil: ser pai de adolescente. Diário da Manhã, Goiânia, 21.05.1995. D. M. Revista, p. 1.

09. TIBA, I. Adolescência: o despertar do sexo. São Paulo: Editora Gente, 1994.

10. ZAGURY, T. Educar sem culpa: a gênese da ética. 3a. ed. Rio de Janeiro:

Record, 1994. 